\title{
Coupling local renewable energy production with electric vehicle charging: a survey of the French case
}

\author{
Paul Codani* \\ Advanced Technologies and Innovation Research Department, \\ PSA Peugeot Citroen, \\ Velizy-Villacoublay, 78140, France \\ and \\ Group of Electrical Engineering - Paris (GEEPs), \\ UMR CNRS 8507, CentraleSupelec, \\ Univ Paris-Sud, Sorbonne, \\ Universites, UPMC Univ Paris 06, \\ Gif-Sur-Yvette, 91190, France \\ Email: paul.codani@supelec.fr \\ *Corresponding author
}

\section{Pierre-Louis Le Portz, Pierre Claverie and Marc Petit}

Group of Electrical Engineering - Paris (GEEPs), UMR CNRS 8507, CentraleSupelec,

Univ Paris-Sud, Sorbonne,

Universites, UPMC Univ Paris 06, Gif-Sur-Yvette, 91190, France

Email: marc.petit@supelec.fr

\section{Yannick Perez}

\section{RITM Lab,}

University of Paris-Sud, 91400 Orsay, France

Email: yannick.perez@u-psud.fr

\begin{abstract}
The share of renewable energy sources (RES) production in energy mixes, especially the ones of PV panels and wind farms, has been continuously increasing during the last few years. Similarly, a strong development of battery electric vehicles (EV) is expected within the next years. However, these two new innovations could trigger local security issues on electrical grids. One way to mitigate these problems could be to combine the charging periods of the EVs with the local RES production. This paper aims at analysing the possibility to implement this kind of smart charging strategy in France by 2020, taking into account the wide diversity of local energy mixes in France and their seasonal dependencies. The results show the achievable green charging ratio for the EV fleet per season and per region, with and without a smart charging strategy.
\end{abstract}

Keywords: coupling; synchronisation; electric vehicles; EV; renewable energy sources; RES; smart charging; charging management; smart grids; France. 
Reference to this paper should be made as follows: Codani, P., Le Portz, P-L., Claverie, P., Petit, M. and Perez, Y. (2016) 'Coupling local renewable energy production with electric vehicle charging: a survey of the French case', Int. J. Automotive Technology and Management, Vol. 16, No. 1, pp.55-69.

Biographical notes: Paul Codani received his MSc in Energy Engineering from Supelec University, Paris, and MSc in Physics and Engineering of Energy from University of Paris-Sud, Paris, in 2013. He is currently pursuing his $\mathrm{PhD}$ on Grid Integrated Vehicles from Supelec University. His $\mathrm{PhD}$ is funded by PSA Peugeot Citroen.

Pierre-Louis Le Portz received his BSc in Engineering from Centrale University, Paris, in 2014. Currently, he is pursuing his MSc in Energy Engineering from CentraleSupelec University.

Pierre Claverie received his BSc in Engineering from Centrale University, Paris, in 2014. Currently, he is pursuing his MSc in Energy Engineering from CentraleSupelec University.

Marc Petit is a former student of the Ecole Normale Superieure de Cachan (France). He took his PhD thesis in 2002 in Electrical Engineering. Since 2003 he is an Assistant/Associate Professor in Supelec in the Power and Energy Systems Department where he currently manages the power system group. Since November 2011, he is co-head of the Armand Peugeot Research Chair on Electromobility. His research interests are on smart grids, demand response, power system protection and HVDC supergrids.

Yannick Perez received his Master's degree and $\mathrm{PhD}$ in Economics at University La Sorbonne in France. He became Assistant Professor at University of Cergy (2000-2003) and tenured Associate Professor of Economics at University Paris-Sud 11 (since 2003). At University Paris-Sud, he is the Academic Coordinator of the European Master Erasmus Mundus in Economics and Management of Network Industries. Since September 2011, he is also an Associate Professor of Economics in CentraleSupelec, France. Since February 2012, he joined the Armand Peugeot Research Chair on Electromobility as an Associate Researcher. His special fields of interest included energy market design and economics of regulation.

This paper is a revised and expanded version of a paper entitled 'Coupling local renewable energy production with electric vehicle charging: a survey of the French case' presented at the 2nd Electromobility: Challenging Issues, Paris, 18-19 December 2014.

\section{Introduction}

European energy-climate objectives for 2030 have just been set by European leaders to a $40 \%$ reduction in $\mathrm{CO}_{2}$ emissions, a $27 \%$ share of renewable energy sources (RES) in the energy mix, and a $27 \%$ increase in energy efficiency. These environmental friendly policies foster the development of RES, mainly through the deployment of PV panels and wind farms. 
Similarly, plug-in electric vehicles (EV) moved by electric motors and powered by electrochemical batteries represent a promising solution with respect to these goals. With the upcoming decrease in battery costs, and the deployment of charging stations, EV or plug-in hybrids sales are expected to increase within the next few years.

However, the increasing penetration of these two new innovations brings up concerns regarding their impacts on the electrical grid security: on one hand, RES are asynchronous and intermittent by nature, and distributed mostly at the distribution grid level. They could trigger local congestion, frequency and voltage-related problems, as well as system wide balancing issues (Sharma et al., 2011; Eftekharnejad et al., 2013; O'Sullivan et al., 2014); on the other hand, if these innovation are not managed properly, the massive introduction of plug-in vehicles could jeopardise grid security (Darabi and Ferdowsi, 2011; Green et al., 2011; Clement-Nyns et al., 2011).

Nevertheless, EVs have a good charging flexibility. In France, a vehicle is used in average 6 hours a week, for a daily commuting trip of $24 \mathrm{~km}$ (CGDD, 2011), what would lead to an approximate daily energy consumption of $4.2 \mathrm{kWh}$. Moreover, when considering a fleet of EVs, the share of EVs being parked never falls below $75 \%$ (Pearre et al., 2011). As a consequence, using EVs as buffer storage units to level the production of RES appears as a promising innovative solution.

The coupling of RES and EVs would require to synchronise EV charging periods with RES production periods and - if vehicle-to-grid (V2G) capabilities are available - to discharge EVs in case of substantial RES production shortfall. This solution could increase the maximum penetration level of RES, as well as the 'green charging' ratio of EVs. This concept has been intensively studied in the scientific literature since its first introduction in 1997 (Kempton and Letendre, 1997). We find that most of the literature either considers the balance between RES production and EV charging at the system-wide scale (Hu et al., 2013; Kempton and Tomić, 2005; Budischak et al., 2013), or in islanded systems watching over frequency deviations (Almeida et al., 2011; Perez et al., 2015).

However, although the system-wide balancing mechanism performed by the transmission system operator (TSO) is of paramount importance, distribution network congestion and voltage constraints should also be considered. Indeed, most of RES are integrated as distributed generation (DG), that is at the distribution network level (RTE, 2013). Furthermore, the 2015 'energy transition law' is expected to encourage innovative decentralised generation and management of the local electricity grid. More precisely, the French minister of ecology has announced the creation of 200 'Territoires a Energie Positive' (TEPOS). Such TEPOS should have $100 \%$ of their demand supplied by local RES (Ministere du Developpement Durable, 2014).

In this context, we propose to study, for the French case in 2020, the possibility to couple RES production with EVs smart charging at the local scale. In order to do so, several local French electricity mixes are studied. Based on these observations, four scenarios representing the main energy mixes are built. For each mix, we propose an unidirectional energy management system (EMS) to optimise the EV charging strategies with RES local production.

The paper is organised as follows. Section 2 deals with the survey of the various local electricity mixes in France. Section 3 presents the EV fleet model as well as the EMS strategy. Results and discussions are provided in Section 4. Section 5 is the conclusions. 


\section{Local electricity mixes in France}

As RES are mainly integrated at the distribution grid level and as local network management is increasingly considered by policy makers, we are concerned with the coupling of RES production and EV charging at the local scale - namely, at the medium voltage (MV) substation level (usually 63 to $21 \mathrm{kV}$ voltage drop). However, local energy mixes vary a lot from one place to the other and from one season to the other. The aim of this section is to analyse these differences in energy mixes depending on the geographical location and on the season, in France.

\subsection{Data}

We used publicly available data from Reseau de transport d'Electricite (RTE), the French $\mathrm{TSO}$, in order to identify the different local generation mixes in France. These data are freely available online (RTE, 2014b). They provide the installed RES capacity by energy source and by region, the instantaneous power production by energy source and by region as well as the instantaneous power consumption by region (with a 30 minute time stamp, over the year 2013).

\subsection{Sample characteristics}

We studied all the 21 regions of metropolitan France, focusing on the production of wind farms and PV panels, as well as on their installed capacity. Results show a wide diversity of local energy mixes between the regions, both in terms of installed capacity and in terms of instantaneous production. Figure 1 shows the installed capacities of respectively wind farms and PV panels in each region.

Figure 1 Installed wind and PV power capacities by region in France (MW) (see online version for colours)

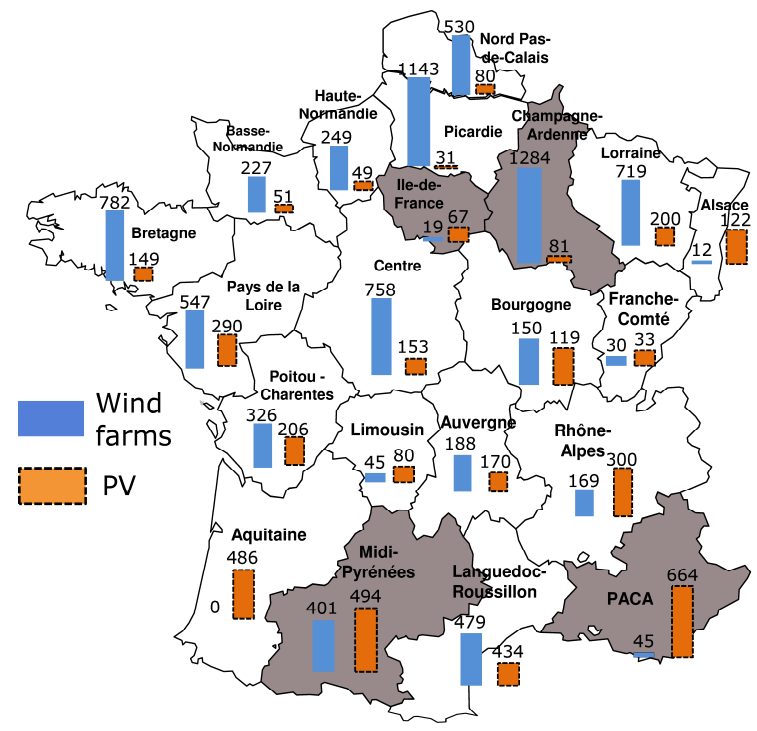

Note: The four regions surveyed in more details are highlighted in dark grey. 
In France, installed capacities of wind and PV are regionally different and reflect partially the local potential for renewables considering seasonal aspects. As a consequence, France exhibits very different regional profiles for RES and EV possible coupling strategies. In the South of France, the regions typically have a substantial amount of PV installed capacity in comparison with their wind power capacity. Thus, there are major differences in RES production between the seasons; indeed, in sunny summer the production will exceed by far the one in gloomy winter. In the North of France, the wind farm installed capacities are more important than those of PV panels. These regions will undergo less seasonal dependencies. Finally, some other regions perform very bad in terms of installed capacity and have few RES resources to optimise.

Figure 2 shows the production in two typical regions over one day, highlighting intraday variations.

Figure 2 RES production in (a) PACA and (b) CE regions on December 17th, 2013 (see online version for colours)

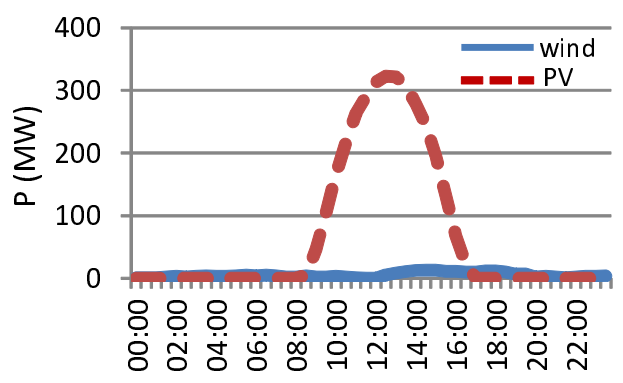

(a)

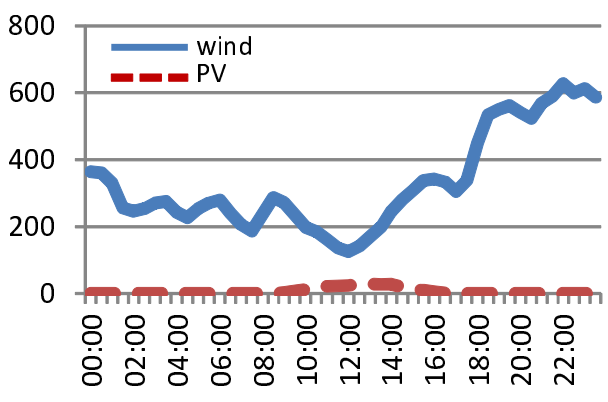

(b)

\subsection{Selection of typical regions}

In order to conduct our simulations at the MV substation level, we need first to select some of the aforementioned regions, with various electricity mixes, and then to scale their instantaneous production at the substation level. Our selection should comprise all the different existing energy mixes and various EVs potential development forecasts.

After having analysed carefully all the 21 French regions, we retain the four next ones (please refer to Figure 1 for their precise location where they are highlighted in dark grey):

- Ile-de-France region: this region typically has low RES production, either from PV panels or from windmills. Moreover, in this very dense and rather rich area, we expect to have a high number of EVs.

- Champagne-Ardenne (CA) region: this region typically has a significant wind power production, but a low $\mathrm{PV}$ production. As CA region is not very economically dynamic (in terms of share of the national GDP) and not densely populated, we expect to have a low number of EVs. 
- PACA region: on the contrary, this sunny region has an important PV production capacity in comparison with its wind farm capacity. In this very dense and rather rich area, we expect to have a high number of EVs.

- Midi-Pyrenees (MP) region: this region has a more diversified energy mix, with almost as much wind capacity as PV capacity. As MP region is not very economically dynamic too, we expect to have a low number of EVs.

Table 1 sums up the particularity of each selected region with respect to their expected RES production and EV development forecasts.

Table 1 The rationale for region selection

\begin{tabular}{|c|c|c|}
\hline EV take rate & Two RES sources & One RES source \\
\hline Low & MP & $\mathrm{CA}$ \\
\hline High & IDF & PACA \\
\hline
\end{tabular}

In France, there are $N_{t}=2,240$ substations (ERDF, 2014). In order to scale the region production to the substation level, we have to define the number of substation in each region; however, this data is not publicly available, so we deduce it by scaling the number of substations in a region $r, N_{r}$, proportionally to its yearly consumption share over one year [using data from RTE (2014b)], according to equation (1):

$$
N_{r}=N_{t} \times \frac{C_{r}}{C_{t}}
$$

with $C_{r}$ and $C_{t}$ the total yearly consumption of the region in question and of all the regions, respectively. As a result, the number of substations per region is provided in Table 2.

Table 2 Calculated number of substations per region

\begin{tabular}{lc}
\hline Region & Number of substations \\
\hline Ile-de-France & 345 \\
Champagne-Ardenne & 50 \\
PACA & 194 \\
Midi-Pyrenees & 94 \\
\hline
\end{tabular}

There are many substations in IDF region because it is the densest region of all. PACA also concentrates many inhabitants. On the contrary, CA and MP regions are less densely populated.

In order to assess the PV and windmills productions in 2020, we consider that the yearly regional penetration rate during the coming years is equal to the last non-null yearly penetration ratio of $\mathrm{PV} /$ wind capacity in the considered region. With this rather simple solution to forecast the 2020 period, we have similar results than the one projected by the French TSO (RTE, 2014a). 


\section{Electric vehicle fleet modelling}

\subsection{Electric vehicle characteristics}

Based on RTE forecasts (RTE, 2014a), we assume that there will be $N_{E V}=500,000 \mathrm{EVs}$ on the French roads by 2020. We deduce the number of EVs in each region $r, N_{E V_{r}}$, in proportion to the regional gross national product (GNP) share [data from INSEE (2014)], according to equation (2):

$$
N_{E V_{r}}=N_{E V} \times \frac{G N P_{r}}{G N P_{t}}
$$

with $G N P_{r}$ and $G N P_{t}$ the regional and national GNP, respectively. Finally, the number of EVs per region and per substation is provided in Table 3.

Table 3 Number of EVs per region and per substation

\begin{tabular}{lc}
\hline Region & Number of EV s per substation \\
\hline Ile-de-France & 445 \\
Champagne-Ardenne & 185 \\
PACA & 183 \\
Midi-Pyrenees & 214 \\
\hline
\end{tabular}

We assume that all the vehicles are full-electric vehicles, with a battery capacity of $22 \mathrm{kWh}$ (which corresponds to $65 \%$ of the EV battery capacities in France in 2013). We add the constraint $0.2<S O C / S O C_{\max }<0.9$ with $S O C$ and $S O C_{\max }$ respectively the current and maximum state of charge (SOC) of the battery; these limits are commonly accepted as those within which batteries should operate in order not to undergo too significant battery wear. The efficiency of the bidirectional chargers was not taken into in this work; the authors are currently conducting efficiency evaluation tests on a bidirectional EV, and the preliminary results suggest a very wide efficiency range over the entire power curve. As a consequence, the authors do not find it satisfactory to consider a steady efficiency of $10 \%$ as a rule of thumb.

The EV trip characteristics are based on several references: internal PSA Peugeot Citroen data, ministerial surveys (CGDD, 2011) and demonstration project results (Cross-border Mobility for EVs, 2013). The EV fleet model is stochastic and dynamic. EV average distance trips $(D)$, departure time $\left(T_{d}\right)$, daily number of trips $(N)$ and seasonal energy consumption $(E)$ are provided in Table $4 . D$ and $T_{d}$ are distributed according to Gaussian distributions with mean $\mu$ and standard deviations $\sigma$. It is noticeable that our model only covers people commuting back and forth to work during week days. During week-ends, EVs are assumed to be full time plugged-in at home.

Obviously, covering only commuting trips in week days is not completely satisfactory. Future work will definitely consist in enlarging the authors' databases in order to improve these routines. However, these trips can be considered as very structuring since they account for most of the trips and driven kilometres in France (CGDD, 2010), what makes our results a first good estimation base. 
Table 4 EV trip characteristics

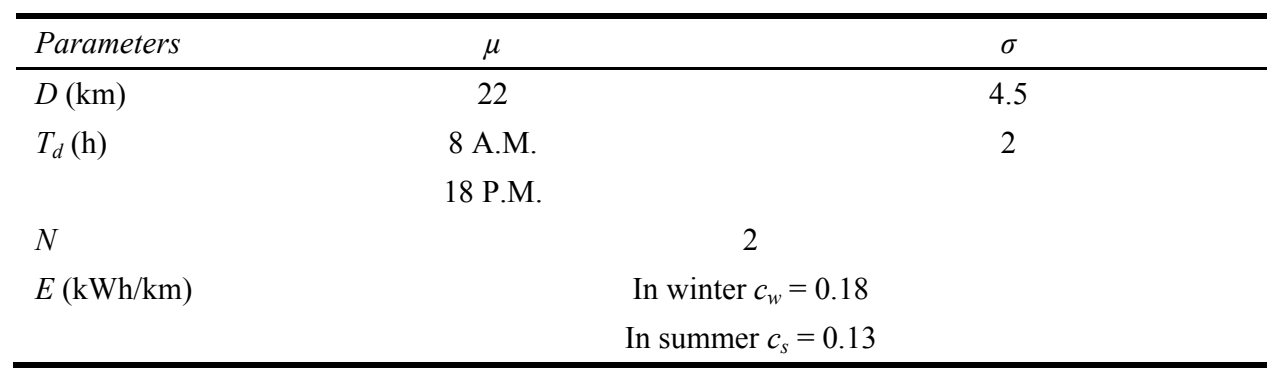

\subsection{Charging station characteristics}

Under our assumptions, EV owners commute back and forth to work every day - apart from weekend periods. Thus, they can charge either at home, on their primary electric vehicle supply equipment (EVSE), or at work on their secondary EVSE. EVSE characteristics are based on French ministerial forecasts (CGDD, 2013). The repartition of the EVSE powers depending on their location is provided in Table 5. We consider usual power levels corresponding to existing charging stations in France - that is, $3 \mathrm{~kW}$, $7 \mathrm{~kW}, 22 \mathrm{~kW}$ and $43 \mathrm{~kW}$. Home charging is mainly done at low power, while working charging stations are more equally distributed (although fast charging is still marginal).

Table 5 EVSE breakdown per charging power in 2020

\begin{tabular}{lcc}
\hline EVSE power plug $(\mathrm{kW})$ & Primary EVSE & Secondary EVSE \\
\hline Slow A $-3 \mathrm{~kW}$ & $93 \%$ & $35 \%$ \\
Slow B $-7 \mathrm{~kW}$ & $7 \%$ & $34 \%$ \\
Intermediate charging $-22 \mathrm{~kW}$ & $0 \%$ & $29 \%$ \\
Fast charging $-43 \mathrm{~kW}$ & $0 \%$ & $2 \%$ \\
\hline
\end{tabular}

For primary EVSEs, we assume that all EV owners have an EVSE at home. Regarding the penetration of EVSEs at work (secondary EVSES), we consider two extreme scenarios:

- scenario A: the penetration of secondary EVSE is $0 \%$ (no EV owner is able to charge at work)

- $\quad$ scenario B: the penetration of secondary EVSE is $100 \%$ (all EV owners are able to charge at work).

\subsection{EMS implementation}

The aim of the EMS is to maximise the 'green charging ratio' of the EVs.

In order to define our 'green charging ratio', we only consider the current and forecasted investments in wind and PV technologies and set aside the previously installed green energies like hydro or biomass. The main reason we focus on 'new renewable' main investment sources is that they are commonly considered as a threat toward the network safety and management in their actual dynamics. 
In this paper, we want to investigate the positive outcomes of coupling RES and PV at the local network level and see how the decentralised solution management system we propose can be a positive resource for local networks.

At each time stamp, the EV fleet can be divided into two groups: the EVs that need to charge at full power for transportation needs, which are not flexible, and the other EVs, which are flexible. The latter are available for the EMS. Each EV $i$ from this category provides the EMS with its available charging power $P_{\text {charg }}^{i}$ for the next time stamp:

$$
P_{\text {charg }}^{i}(t)=-\min \left(P_{E V S E}^{i}, \frac{S O C_{\max }^{i}-S O C^{i}(t)}{\Delta t}\right)
$$

with $P_{E V S E}^{i}$ the EVSE power, $\Delta t$ the simulation time stamp (30 minutes), $S O C_{\max }^{i}$ and $S O C^{i}(t)$ respectively the maximum and current $\mathrm{SOC}$ of the battery (negative power values stand for EV charging mode).

Then, depending on the current RES production $P_{R E S}(t)$, the EMS computes the required charging power from the available $\mathrm{EVs} P_{E V_{E M S}}(t)$ :

$$
P_{E V_{E M S}}(t)=\max \left(\sum_{i} P_{\text {charg }}^{i}(t),-P_{R E S}(t)\right)
$$

We assume that the EMS has a very precise forecast of the RES production over the next time frame (15 minute), what seems plausible considering today forecast accuracies of roughly one hour for wind and solar electricity generation.

Once the required charging power has been computed, it has to be dispatched among the available EVs. The strategy implemented consists in charging successively the EVs in ascending order of SOC.

Figure 3 shows the EV charging patterns over one day (March 1st, 2013) both in the uncontrolled - i.e. EVs have a simple charge-as-plugged strategy - and controlled scenarios i.e. EV charging patters are controlled by the EMS. The EMS strategy is clear on this figure: EV charging periods are synchronised with RES production periods.

Figure 3 EV load curve and RES production curve in March 1st, 2013 for controlled and uncontrolled strategies under scenario A, (a) uncontrolled charging (b) controlled charging (see online version for colours)

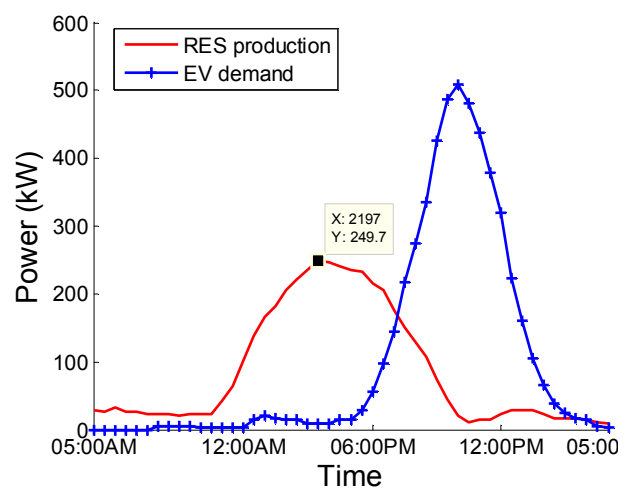

(a)

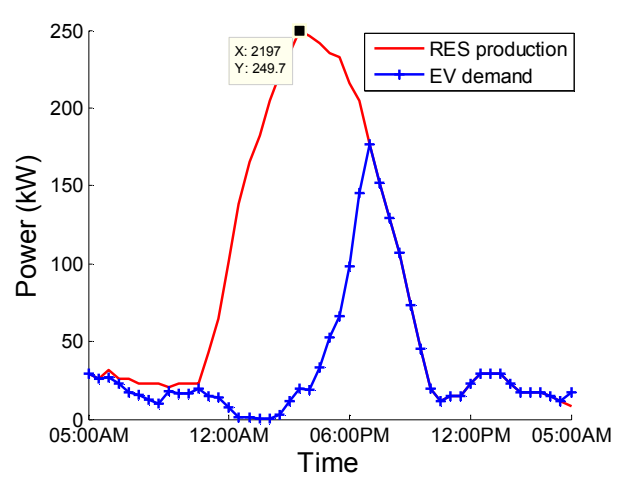

(b) 


\section{Results and discussions}

We perform simulations over one year with a 15 minute time stamp, for the four regions identified in Section 2.3. For each simulation, we evaluate the green charging ratio of our modelled EV fleet, defined by the overall energy percentage that was charged using local RES production. We consider two different charging strategies: the uncontrolled charging which only allows EVs to 'charge as plugged'; and a second strategy in which the EMS maximises the green charging ratio for EVs.

\subsection{Uncontrolled charging}

In this scenario, the EVs implement a 'charge-as-plugged' strategy, meaning that all EV owners will plug their EVs as soon as they can, and EVs will charge as soon as they are plugged in. Under this uncoordinated scenario, some wastes of RES production are expected to happen and we anticipate them to be worse in the case of regions having a single RES available. Results are provided in Table 6, for each region and per season. A distinction is made between scenario $A(0 \%$ EVSE at working places) and scenario $B$ (100\% EVSE at working places).

Table 6 Green charging ratio, uncontrolled charging strategy

\begin{tabular}{|c|c|c|c|c|c|}
\hline \multirow{2}{*}{ Region } & \multirow{2}{*}{ Scenario } & \multicolumn{4}{|c|}{ Green charging ratio (\%) } \\
\hline & & Jan-Mar & Apr-Jun & Jul-Sep & Oct-Dec \\
\hline \multirow[t]{2}{*}{ IDF } & A & 7.7 & 23.0 & 24.5 & 13.0 \\
\hline & $\mathrm{B}$ & 14.4 & 36.2 & 35.2 & 16.8 \\
\hline \multirow[t]{2}{*}{$\mathrm{CA}$} & $\mathrm{A}$ & 98.8 & 99.8 & 99.9 & 98.8 \\
\hline & $\mathrm{B}$ & 99.5 & 99.9 & 99.9 & 99.3 \\
\hline \multirow[t]{2}{*}{ PACA } & A & 56.4 & 82.5 & 77.4 & 53.3 \\
\hline & $\mathrm{B}$ & 80.1 & 91.3 & 87.8 & 76.4 \\
\hline \multirow[t]{2}{*}{ MP } & A & 93.9 & 99.1 & 98.5 & 95.6 \\
\hline & $\mathrm{B}$ & 97.8 & 99.7 & 99.2 & 98.0 \\
\hline
\end{tabular}

The first result from our simulations is that there is not any scenario, with the solution 'charge as plugged' by 2020, in which RES production and EVs charging are perfectly coupled. The worst GCR is 7.7\% (IDF, January to March, scenario A) and the best is $99.9 \%$.

Our second result is more contrasted. We expected regions with only one RES type available to be less efficient than the regions with balanced energy mix. This trend is not confirmed in our results due to the relative abundance of RES production levels compared to EVs demand forecasts.

Our third result measures the actual diversity from one region to another and from one season to another. The seasonal dependency is substantial in the IDF region, with a GCR during sunny periods twice to three times as high as the GCR computed in winter periods. This is due to the importance of the PV production in the GCR values, what can be also understood from the GCR improvement from scenario A to scenario B. On the contrary, the CA region, due to its very high wind production, has a very high GCR for 
all the scenarios and all the seasons. This trend can also be observed in the MP region, although the GCR falls down to $93 \%$ from January to March under scenario A. Finally, the GCR of the PACA region is extremely sensitive to the solar radiation: there are significant differences in GCR between the seasons, and between scenarios A and B.

\subsection{Controlled charging}

In this scenario, the EV charging decisions are controlled by the EMS described in Section 3.3. Results are provided in Table 7.

Table 7 Green charging ratio, controlled charging strategy

\begin{tabular}{lccccc}
\hline \multirow{2}{*}{ Region } & Scenario & \multicolumn{5}{c}{ Green charging ratio (\%) } \\
\cline { 3 - 6 } & & Jan-Mar & Apr-Jun & Jul-Sep & Oct-Dec \\
\hline IDF & A & 30.4 & 58.3 & 59.5 & 41.3 \\
& B & 39.3 & 82.0 & 83.6 & 45.3 \\
CA & A & 100 & 100 & 100 & 100 \\
& B & 100 & 100 & 100 & 100 \\
& A A & 98.9 & 99.2 & 98.4 & 95.5 \\
\multirow{3}{*}{ MP } & B & 100 & 100 & 100 & 100 \\
& A & 100 & 100 & 100 & 100 \\
& B & 100 & 100 & 100 & 100 \\
\hline
\end{tabular}

The first noticeable result is the great improvement in GCR values: in 20 out of 32 scenarios, we achieve to have a perfect coupling of RES production and EVs charging. In all these cases, our EMS helps to better manage locally the coupling of RES and EVs.

The diversity of 12 incomplete GCR needs a further analysis: our results show significant differences between the regions. In regions CA and MP, the green charging ratio (GCR) achieved is $100 \%$ in all seasons and both scenarios. However, the GCR of these regions was already very high without controlling the charging patterns of the EVs. Similarly, in the PACA region, the GCR attained is $100 \%$ (or close) for all seasons and all scenarios. Thus, the GCR has been much improved in PACA, especially under the hypothesis of scenario A, compared to its value in the uncontrolled case study.

Finally, the IDF region GCR has also been significantly increased by means of the EMS strategy. Nevertheless, its value is still quite low in winter seasons, and under scenario A hypothesis. Table 8 provides the conclusion of the interest of using our EMS to improve the coupling of RES with EVs.

Table 8 The interest in implementing an EMS

\begin{tabular}{lcc}
\hline EV take rate & RES available & One RES source \\
\hline Low & MP: low & CA: low \\
High & IDF: high & PACA: high \\
\hline
\end{tabular}


Our simulations clearly show that our approach is more useful in regions where the number of EVs is forecasted to be significant and where RES are mainly consisted of solar sources.

\subsection{Discussions}

From the previous results, we can identify different trends in the regions ability to provide the EVs with a good GCR. First, there are the regions that do not need any EMS; the RES production is important compared to the EV consumption and occurs at EV charging periods. These regions correspond to the CA and MP case studies. Then, there are the regions - such as the PACA one - which have a sufficient level of RES production, but in which the latter is not synchronised with the EV charging periods. In this case, the implementation of an EMS to couple EV charging periods and RES production can have a substantial impact on the achieved GCR. Finally, there are the regions in which the EV energy consumption exceeds the RES production capability namely, the IDF region. In this kind of region, implementing an EMS can improve the GCR, but the latter will not be able to reach $100 \%$. Figure 4 and Figure 5 show the GCR evolutions over one year for PACA and IDF regions, for scenarios A and B.

Figure 4 Green charging ratio for PACA over one year (starting January 1st), for both charging strategies and both scenario, (a) uncontrolled, scenario A (b) uncontrolled, scenario B (c) controlled, scenario A (d) controlled, scenario B (see online version for colours)

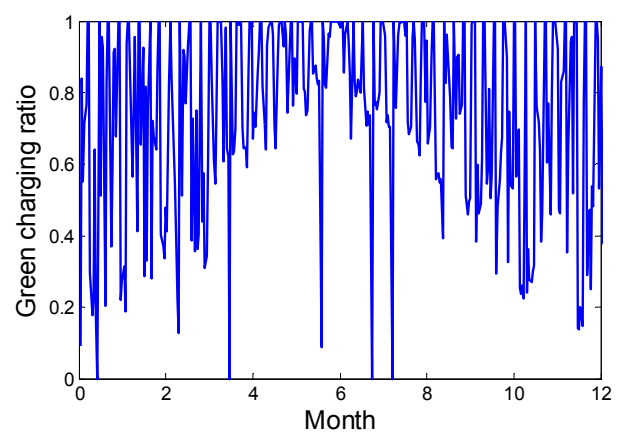

(a)

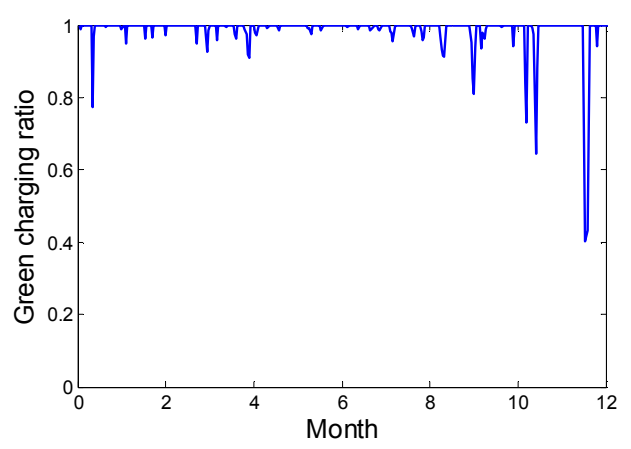

(c)

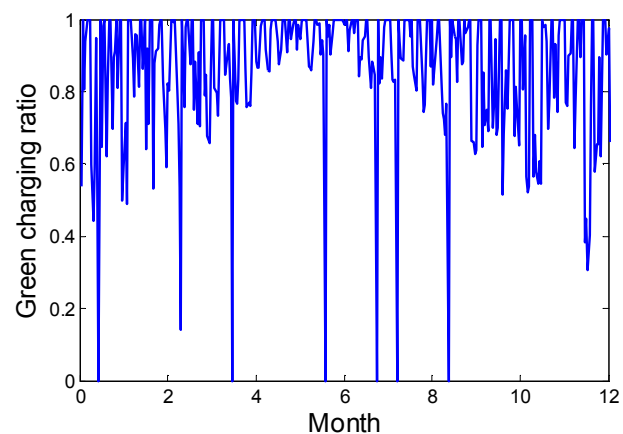

(b)

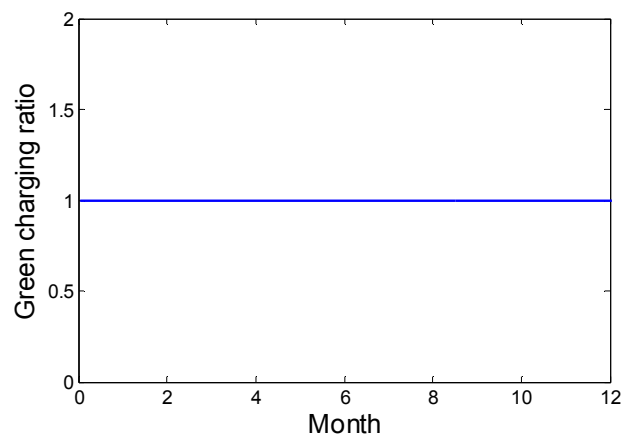

(d) 
Figure 5 Green charging ratio for IDF over one year (starting January 1st), for both charging strategies and both scenario, (a) uncontrolled, scenario A (b) uncontrolled, scenario B (c) controlled, scenario A (d) controlled, scenario B (see online version for colours)

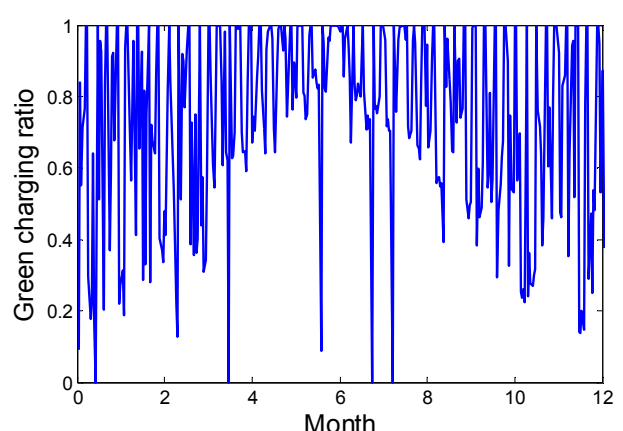

(a)

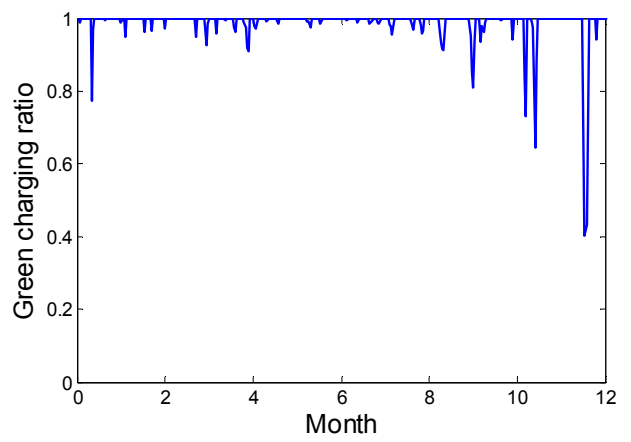

(c)

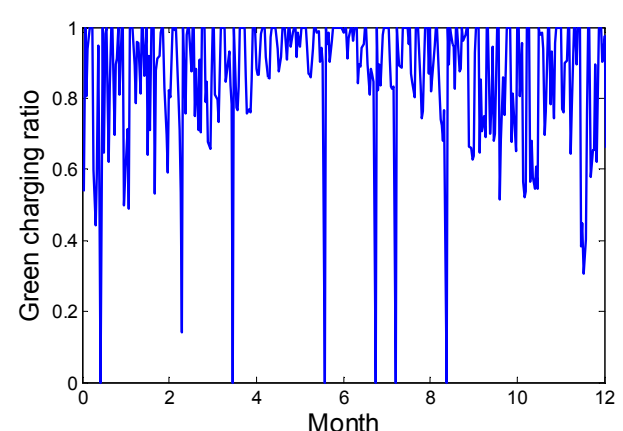

(b)

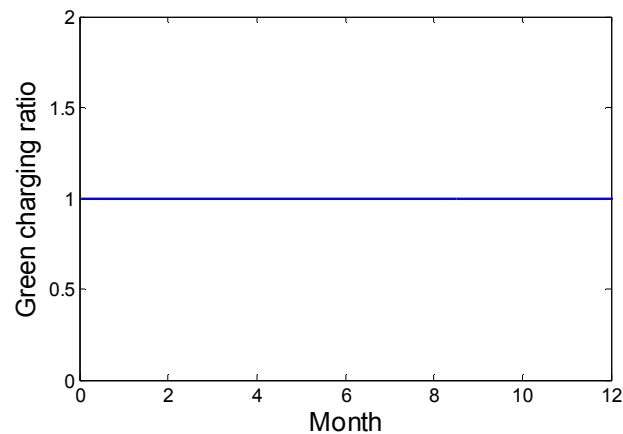

(d)

\section{Conclusions}

Managing EV charging periods in order to maximise the green charging ratio of the EV fleet could be a way to mitigate local grid issues (voltage control, congestion) and to improve local consumption. However, local energy mixes can be very different from each other, and this diversity should be considered when mentioning this solution.

In this paper, the authors tackle the French case in 2020 . We demonstrate first that there is indeed a great diversification of local energy mixes in France. This leads to very different green charging ratio when not considering any smart charging strategy: we have results ranging from $7.7 \%$ for the IDF region, in winter with scenario A to almost $100 \%$ for the CA region, for all seasons and both scenarios.

The EMS is able to increase the GCR of regions that had a rather low one without EMS. This is in particular true for the PACA and IDF regions, where the EV charging periods were poorly synchronised with the RES production.

Future work could be to conduct this analysis for all the 22 regions in France. We also plan to look into the maximum number of EVs that could be integrated in each region in 2020 with a minimum level of GCR. At last, we could also include more uncertainty in the RES production forecast. 


\section{Acknowledgements}

This research benefits from the support of the Chair 'PSA Peugeot Citroen Automobile: Hybrid technologies and Economy of Electromobility', so-called Armand Peugeot Chair led by Ecole CentraleSupelec, ESSEC and sponsored by PEUGEOT CITROEN Automobile.

\section{References}

Almeida, P.M.R., Lopes, J.A.P., Soares, F.J. and Seca, L. (2011) 'Electric vehicles participating in frequency control: operating islanded systems with large penetration of renewable power sources', in 2011 IEEE Trondheim PowerTech, Vol. 1, pp.1-6, IEEE, doi:10.1109/PTC.2011.6019424.

Budischak, C., Sewell, D., Thomson, H., Mach, L., Veron, D.E. and Kempton, W. (2013) 'Cost-minimized combinations of wind power, solar power and electrochemical storage, powering the grid up to $99.9 \%$ of the time', Journal of Power Sources, Vol. 225, pp.60-74, doi:10.1016/j.jpowsour.2012.09.054.

CGDD (2010) La mobilité des Français, panorama issu de l'enquête nationale transports et déplacements 2008 [online] http://www.developpement-durable.gouv.fr/IMG/pdf/Rev3.pdf (accessed 22 October 2015).

CGDD (2011) Les vehicules electriques en perspectives [online] http://www.developpementdurable.gouv.fr/IMG/pdf/ED41.pdf (accessed 16 September 2015).

CGDD (2013) Livre Vert sur les infrastructures de recharge ouvertes au public pour les vehicules decarbones [online] http://www.developpement-durable.gouv.fr/Livre-Vert-sur-lesinfrastructures.html (accessed 22 October 2015).

Clement-Nyns, K., Haesen, E. and Driesen, J. (2011) 'The impact of vehicle-to-grid on the distribution grid', Electric Power Systems Research, Vol. 81, No. 1, pp.185-192.

Cross-border Mobility for EVs (2013) Project Results [online] http://crome.forschung.kit.edu/ francais/57.php (accessed 22 October 2015).

Darabi, Z. and Ferdowsi, M. (2011) 'Aggregated impact of plug-in hybrid electric vehicles on electricity demand profile', IEEE Transactions on Sustainable Energy, Vol. 2, No. 4, pp.501-508.

Eftekharnejad, S., Vittal, V., Keel, B. and Loehr, J. (2013) 'Impact of increased penetration of photovoltaic generation on power systems', IEEE Transactions on Power Systems, Vol. 28, No. 2, pp.893-901.

ERDF (2014) Fonctionnement du reseau [online] http://www.erdf.fr/fonctionnement_du_reseau (accessed 3 December 2014).

Green, R.C., Wang, L. and Alam, M. (2011) 'The impact of plug-in hybrid electric vehicles on distribution networks: a review and outlook', Renewable and Sustainable Energy Reviews, Vol. 15, No. 1, pp.544-553.

Hu, W., Su, C., Chen, Z. and Bak-jensen, B. (2013) 'Optimal operation of plug-in electric vehicles in power systems with high wind power penetrations', IEEE Transactions on Sustainable Energy, Vol. 4, No. 3, pp.577-585.

INSEE (2014) French Regional GNP [online] http://www.insee.fr/fr/themes/detail.asp?reg_id= 99\&ref id=pib-va-reg-base-2005 (accessed 15 December 2014).

Kempton, W. and Letendre, S. (1997) 'Electric vehicles as a new power electric utilities source for electric utilities', Transportation Research Part D: Transport and Environment, Vol. 2, No. 3 , pp.157-175.

Kempton, W. and Tomić, J. (2005) 'Vehicle-to-grid power implementation: from stabilizing the grid to supporting large-scale renewable energy', Journal of Power Sources, Vol. 144, No. 1, pp.280-294. 
Ministere du Developpement Durable (2014) Territoires à Energie Positive [online] http://www.territoires-energie-positive.fr/ (accessed 2 December 2014).

O'Sullivan, J., Rogers, A., Flynn, D., Smith, P., Mullane, A. and O’Malley, M. (2014) 'Studying the maximum instantaneous non-synchronous generation in an island system frequency stability challenges in Ireland', IEEE Transactions on Power Systems, Vol. 29, No. 6, pp.2943-2951.

Pearre, N.S., Kempton, W., Guensler, R.L. and Elango, V.V. (2011) 'Electric vehicles: how much range is required for a day of driving?', Transportation Research Part C: Emerging Technologies, Vol. 19, No. 6, pp.1171-1184.

Perez, Y., Petit, M., Ramos-Real, F.J. and Marrero, G. (2015) 'Electric vehicle fleet contributions for isolated systems. The case of the canary islands', International Journal of Automotive Technology and Management (IJATM), Vol. 15, No. 2, pp.171-193.

RTE (2013) Panorama des énergies renouvelables [online] http://www.rtefrance.com/sites/default/files/panorama_des_energies_renouvelables_2014.pdf (accessed 06-10-2015).

RTE (2014a) Bilan previsionnel de l'equilibre offre-demande d'electricite en France [online] http://www.rte-france.com/fr/article/bilan-previsionnel (accessed 22 October 2015).

RTE (2014b) Eco2Mix [online] http://www.rte-france.com/fr/eco2mix/eco2mix (accessed 2 December 2014).

Sharma, S., Huang, S-H. and Sarma, N. (2011) 'System inertial frequency response estimation and impact of renewable resources in ERCOT interconnection', in 2011 IEEE Power and Energy Society General Meeting, pp.1-6, IEEE, doi:10.1109/PES.2011.6038993.

\section{Appendix}

\section{Region characteristics}

Table 9 provides an overview of the main characteristics of the four regions understudy.

Table 9 Calculated number of substations per region

\begin{tabular}{lcccccc}
\hline Region & $\begin{array}{c}\text { Yearly } \\
\text { cons. share }\end{array}$ & $\begin{array}{c}\text { Number of } \\
\text { substations }\end{array}$ & $\begin{array}{c}\text { Installed } \\
\text { PV } \\
\text { capacity }\end{array}$ & $\begin{array}{c}\text { Installed } \\
\text { wind } \\
\text { capacity }\end{array}$ & GDP share & $\begin{array}{c}\text { Number of } \\
\text { EVs per } \\
\text { substation }\end{array}$ \\
\hline IdF & $15.4 \%$ & 345 & $129 \mathrm{MW}$ & $19 \mathrm{MW}$ & $30.7 \%$ & 445 \\
CA & $2.2 \%$ & 50 & $168 \mathrm{MW}$ & $2,989 \mathrm{MW}$ & $1.9 \%$ & 185 \\
PACA & $8.7 \%$ & 194 & $3,217 \mathrm{MW}$ & $45 \mathrm{MW}$ & $7.1 \%$ & 183 \\
MP & $4.2 \%$ & 94 & $1,645 \mathrm{MW}$ & $543 \mathrm{MW}$ & $4.0 \%$ & 214 \\
\hline
\end{tabular}

